\section{A SOCIOLOGIA DA ARTE ENQUANTO CAMPO DE PESQUISA}

\author{
Caroline de Araújo Lima* \\ Lucas Barreto Catalan**
}

CÂMARA, Antônio da Silva; SILVA, Bruno Evangelista da; LESSA, Rodrigo Oliveira. (Orgs.). Ensaios de Sociologia da Arte. Salvador: EDUFBA, 2018. 260p

O livro "Ensaios de Sociologia da Arte”, lançado em 2018 pela EDUFBA, é uma coletânea dividida em duas partes, com um total de quatro artigos e oito ensaios. Os organizadores, Antônio da Silva Câmara, Bruno Evangelista da Silva e Rodrigo Oliveira Lessa, reconhecidos academicamente por suas produções e por suas publicações no que tange a área da sociologia da arte, são membros fundadores do grupo de pesquisa "representações sociais, arte ciência e ideologia”, sediado na Faculdade de Filosofia e Ciências Humanas Universidade Federal da Bahia (UFBA). Como está explicito no título da obra, o leitor encontrará ensaios que enriquecerão seus conhecimentos relacionados ao campo da sociologia da arte. Bastide (2006) aponta que as pesquisas desse campo são importantes nas Ciências Sociais, já que a arte pode se configurar enquanto ruptura dos indivíduos ao imaginário social ideologizado, colaborando para um novo olhar para o mundo histórico.

Buscando compreender a relação entre arte e sociedade, a primeira parte, intitulada

* Universidade do Estado da Bahia (UNEB) Campus XVIII Av. David Jonas Fadini, 300 - Stela Reis. Cep: 45823-035. Eunápolis - Bahia - Brasil. carolimasantos@gmail.com. https://orcid.org/0000-0003-4069-4302

* * Universidade Federal da Bahia (UFBA)

Estrada de São Lázaro 197, Federaç̃o, Cep: 40.210730 Salvador - Bahia - Brasil. lucatalan@hotmail.com https://orcid.org/0000-0002-6398-4276
"Elementos teóricos da sociologia da arte", composta por quatro artigos, tem por objetivo introduzir o leitor nos princípios teóricos da sociologia da arte, dialogando com os clássicos da filosofia e da sociologia estética, vis-à-vis, Kant (1989), Hegel (1983), Benjamin (1994), Adorno (2008), Luckács (1968). Além de nos apresentar esses princípios teóricos, os autores convidam o (a) leitor (a) a conhecer as discussões relacionadas ao sujeito da criação e à sociologia da percepção artística.

No primeiro artigo, "Pressupostos filosóficos clássicos: sentidos e mediação do pensamento", os autores buscam, primeiramente apresentar a perspectiva estética presente nas obras dos filósofos Kant e Hegel, uma espécie de "filosofia da arte", mostrando a diferenciação de pensamento estético desses dois pensadores. Se, por um lado, Kant percebia o belo artístico enquanto a possibilidade de maior proximidade com o belo natural; o belo para Hegel aparece enquanto uma representação contraditória do real, capaz de carregar, em sua expressão, conteúdos concretos da existência de maneira singular.

É a partir desse ensejo hegeliano que, no segundo artigo, "Aportes do materialismo histórico para a sociologia da arte", é feita uma reflexão acerca das contribuições materialistas históricas para o campo da sociologia da arte, buscando compreender, de maneira mais cuidadosa, a relação entre o mundo histórico e a arte. Toma-se por referência três autores marxistas que pensaram a estética, Benjamim, Luckacs e Adorno, relacionando, primeiramente, o desenvolvimento da arte com as transformações da sociedade moderna, sobretudo com o aprofundamento do capitalismo industrial. Ademais busca-se compreender de que modo, na construção estética, a forma e o conteúdo relacionam-se com o mundo histórico, desenvolvendo conceitos como representação, desantropomorfização, indústria cultural, etc. Outrossim, é trazida a reflexão acerca da capacidade da arte de transcender a realidade imediata em que está inserida, analisando como 
esses autores percebiam a forma singular da estética artística em carregar centelhas de rupturas com o conservantismo do mundo real, capitalista e reificado,

o conhecimento desentroporfizador é aquele no qual a importância das relações entre os homens são recolocadas no seu devido lugar, a 'desfetichização' da realidade objetiva na arte - processo pelo qual a particularidade da obra entra em conexão com a universalidade das questões para quais ela aponta pode ser entendida como a ação de projetar objetividades que se apresentam de maneira independente (Lessa; Junior; Mathias, 2018, p.53).

Após a discussão teórica centrada na sociologia da arte, no terceiro artigo "Considerações acerca do sujeito da criação artística”, apresenta-se elementos teóricos da psicologia da arte para tratar do sujeito da criação, fundamentando-se centralmente nos autores Arnheim e Ostrower, não desconsiderando a filosofia alemã e o conceito de gênio. O binômio autor/obra é basilar para o entendimento da relação entre arte e sociedade, a expressão artística enquanto externalização da subjetividade humana potencializa o objeto arte enquanto um outro singular; como particulariza cada obra à seu eu criador, Para Dewey,

(...) Em uma obra de arte, os diferentes atos, episódios ou ocorrências se desmancham e se fundem na unidade, mas não desaparecem, nem perdem seu caráter próprio ao fazê-lo - tal como, em uma conversa amistosa, há um intercambio e uma mescla continua, mas cada interlocutor não apenas preserva seu caráter pessoal, como também o manifesta com mais clareza do que é seu costume (Dewey, 2010, p.112).

O artigo discorre sobre criação artística como uma expressão da percepção do mundo e não como decorrência direta e única de seu criador. Busca-se transpor a perspectiva reducionista da psicanálise, que configura a arte enquanto simples manifestação do inconsciente do sujeito criador; compreendendo essa criação como um elemento relacional da subjetividade do artista e o mundo social, assim, a arte configura-se como tal "porque ultrapassa os limites de suas determinações, sejam eles psíquicos ou mesmos sociais, de modo que nos surpreende e nos tira do que está posto por seu caráter inovador e inesperado" (Malin, 2018, p. 70).

O quarto artigo "Abordagens sobre a sociologia da recepção artística”, fecha a primeira parte do livro com o debate da sociologia da recepção. Nesse artigo, para o entendimento da produção e da circulação da arte, utiliza-se das contribuições da sociologia da recepção através da autora Heinich e dos autores Bastide e Bourdieu, apontando a existência de outros aportes teóricos da sociologia da arte que buscam compreendê-la por caminhos externos à estética artística. Heinich parte do desenvolvimento analítico da arte, apostando na descrição e na recepção do público que alcança a obra; já Bastide transita da sociologia da arte para a sociologia do público, partindo de um juízo de gosto na construção do valor estético da obra, dialogando assim com a consciência coletiva Durkheimiana; por fim, Bourdieu, busca a compreensão do habitus na relação de produção e circulação da arte em seu campo, como também o capital simbólico que a obra de arte é capaz de construir.

Na parte I, realiza-se uma exposição da fundamentação teórica que consolida a sociologia da arte enquanto campo e disciplina das Ciências Sociais, oferecendo ao (à) leitor (a) suporte metodológico e possibilidades de novos objetos de pesquisa.

Na Parte II, intitulada "As sociologias das artes", na prática, é feito o debate empírico. Composta por oito ensaios, que expõem ao (à) leitor (a) o resultado desse acúmulo teórico, apresentando diversas expressões artísticas enquanto objetos de estudo, e como esses objetos contribuem na percepção do desenvolvimento intrínseco de cada expressão artística e na maneira singular dessa expressão se relacionar com o mundo histórico.

No primeiro Ensaio, "Por uma Sociologia da Pintura”, são resgatados conceitos elaborados por Hegel acerca da arte pictórica, fundamentando a análise desse objeto do ponto de 
vista estético e sociológico. Além de caracterizar aspectos analíticos de forma singular a essa expressão, como o plano, por exemplo, evidencia-se a capacidade das artes plásticas em apreender e em fixar traços da sociedade, "o espaço plástico, nesse sentido, é uma dimensão autônoma que a pintura oferece para problematizar a existência social” (Silva, 2018, p.115). Como uma necessidade de compreender o movimento moderno da pintura, no ensaio, são tecidas reflexões acerca da crise da arte e do desenvolvimento da arte pictórica neste novo momento histórico, suas transformações e suas atualizações. Além disso, apresenta-se a sociologia da pintura enquanto disciplina e a arte pictórica como expressão da sociedade.

No segundo ensaio, "Notas para uma sociologia do romance", os autores iniciam evidenciando a literatura como fornecedora de material para a pesquisa sociológica, em seguida traçam o movimento ocorrido no interior dessa expressão, a começar pela distinção entre o romance moderno e a literatura épica. Fundamentados em Luckács, demonstram como o romance colocou a centralidade no indivíduo, enquanto herói da trama, capaz de romper e de superar a escalada que lhe foi imposta; enquanto o herói épico traz em sua delimitação uma totalidade mais aprofundada, carregando consigo a sua comunidade. Assim, o romance moderno buscou apreender, de forma mais profunda, um particular, trazendo, em sua narrativa, descrições que partem do olhar e da vida individual, rodeada de suas complexidades. Essa forma narrativa gera, esteticamente, uma diminuição considerável da distância existente entre narrador (aquele que antes tudo sabia) e leitor; fazendo com que o romance, representando algo particular, consiga, ainda assim, carregar a obra de arte com aspectos universalizantes, vis-à-vis o "o processo” de Franz Kafka.

O terceiro ensaio, "Contribuição para uma sociologia da fotografia”, é iniciado com contextualização histórica da origem da fotografia e da sua motivação. Evidencia-se o de- senvolvimento dessa enquanto obra singular, caracterizando a relação de proximidade entre a fotografia com outras expressões artísticas, a exemplo do cinema e das artes plásticas. A dualidade da fotografia é apresentada por seu aspecto científico, ancorado em seus elementos técnicos e com sua proximidade ao real; e, por outro lado, pelo conteúdo propriamente artístico, calcado na criatividade do (a) artista. O ensaio trata, sobretudo, da formação da fotografia enquanto expressão artística, perdendo o engajamento analítico sobre a própria expressão.

Quanto à arte cinematográfica, no quarto ensaio, "Notas sobre uma sociologia do cinema", o cinema é localizado historicamente como fruto dos avanços tecnológicos no final do século XIX. Sobre o cinema como obra de arte, o autor explica que tal caracterização parte do seu reconhecimento, enquanto representação e/ou imaginário, como forma de recriação da realidade social. A produção cinematográfica estaria relacionada com o avanço do capitalismo moderno e das suas atividades produtivas, proporcionando a capacidade de se associar com outras formas de expressões artísticas (como a música e a fotografia). Isso possibilita a constituição do cinema como arte singular de representação do mundo moderno e sua inerente dinâmica, "tendo o cinema surgido no âmbito da sociedade capitalista moderna, refletirá em grande parte as tensões e contradições que marcam o desenvolvimento dessa sociedade" (Peixoto, 2018, p.164). Ademais, aponta-se a relação entre o cinema e a sociedade, indicando ao (à) leitor (a) as modificações sofridas com o transcorrer histórico e como as novas abordagens deram formatos diferenciados ao cinema, expressando-se no cinema norte-americano, no realismo soviético, no expressionismo alemão, no neorrealismo italiano e na nouvelle vague. Essas tendências do cinema moderno, considerando as particularidades de cada forma antes mencionada, evidencia o cinema enquanto uma arte em permanente construção e que expressa a realidade social a partir de sua recriação. 
Sobre a música, o quinto ensaio, "Fundamentos de uma sociologia da música”, é iniciado afirmando a música como uma das mais importantes expressões artísticas da humanidade. O objetivo do texto é o estudo da sociologia da música e como essa expressão se relaciona com a sociedade, além de demonstrar as fundamentações teóricas e as possibilidades dessa obra de arte enquanto objeto de estudo nas Ciências Sociais. O autor, ao tratar a estética sociológica, apresenta a música como uma arte que sustenta o seu caráter de representação social, expressando-se através da subjetividade e da sensibilidade do espírito humano. São elencadas as características formadoras da música, como o som, as vibrações, o tempo, o compasso, observando como esses elementos da forma são influenciados por mudanças no mundo histórico, como também, vinculam essa expressão a realidade social a partir de sua forma de representação.

No sexto ensaio, "Apontamentos sobre uma sociologia do teatro", considera-se o teatro como um "fato social total", problematizando a relação teatro x vida, refletindo acerca dos papeis sociais e da própria teatralização da vida, “dessa forma, a verdadeira magia do teatro não está nos encantamentos que produz, mas na possibilidade de mediar o mundo real do mundo representado" (Rocha, 2018, p.209). É dessa relação teatro $\mathrm{x}$ vida social que o palco surge como espaço para interações e conhecimentos i em que passamos a refletir o teatro enquanऽे to mediador do mundo real com o mundo re-
A dança enquanto um ato de viver é uma das argumentações apresentadas no sétimo ensaio, "Reflexões para uma sociologia da dança”. Considerando o difícil percurso para a autonomização da arte em relação à vida cotidiana, a dança foi uma expressão artística que tardou a ser reconhecida como tal pelas elites. A partir de um breve debate teórico, o texto apresenta uma definição preliminar da dança, na perspectiva de compreensão da emancipação da arte das amarras do cotidiano social, a dança "tem um elemento utópico que aponta para a superação do trabalho subsumido à necessidade de satisfação de necessidades materiais que atingiram seu auge na sociedade capitalista” (Câmara; Lima; Araújo, 2018, p.221). A partir dessa perspectiva, os autores trazem essa expressão artística enquanto um não objeto-obra com o objetivo de localizar a dança sociologicamente, tendo em vista a sua relação intrínseca com o contexto histórico, expressando o momento vivido que, por um tempo, marginalizou a dança-espetáculo, mas não apagou a dança clássica. Este ensaio contribui para a reflexão no campo da sociologia da dança, entretanto não explora de forma mais sistemática métodos analíticos do objeto.

No oitavo e último ensaio, "Notas para uma sociologia da performance", o autor faz um breve histórico dessa expressão artística que tem no corpo seu principal suporte. Ela é fruto da arte contemporânea e da perspectiva da rejeição da tradição e do considerado antigo, é a emergência do novo. No decorrer do ensaio, há um debate teórico que coloca a performance dentro da sociologia da arte, um breve histórico da arte contemporânea e como essa expressão pode ser relativizada em relação à rejeição dos ritos. Suas práticas criativas geralmente estariam associadas a relação do sujeito com o mundo, onde o corpo do artista acaba expressando a vida como sua principal matéria-prima.

A Sociologia da Arte, enquanto campo, é o centro do debate na obra, seus artigos e ensaios são resultados da maturidade das 
produções acadêmicas e das pesquisas desenvolvidas no grupo supracitado. Sua fragilidade encontra-se no pouco aprofundamento acerca das teorias contemporâneas da sociologia da arte, estas encontradas apenas em um artigo dos doze trabalhos desenvolvidos no livro. Apesar desta lacuna, a obra é uma leitura obrigatória aos (as) interessados (as) nos estudos relacionados à Arte e à Sociologia da Arte, tendo em vista a riqueza teórica e a maturidade nas análises, orienta teórica e metodologicamente o (a) leitor (a), apontando caminhos para o desenvolvimento das pesquisas sociológicas sobre as diversas expressões artísticas que são objeto de análise da Sociologia.

Recebido para publicação em 21 de março de 2019 Aceito em 14 de novembro de 2020

\section{REFERÊNCIAS}

ADORNO, Theodor W. Teoria Estética. Edições 70. Lisboa. 2008.

BASTIDE, Roger. Problemas da sociologia da arte. In: Tempo Social. Revista de Sociologia da USP. v. 18, n. 2. Novembro de 2006, p. 295-305.

BENJAMIN, Walter. Magia e técnica, arte e política: ensaios sobre literatura e história da cultura: Obras Escolhidas, vol. I. São Paulo: Brasiliense, 1994.
CÂMARA, Antonio da Silva; LIMA, Diogo Souza; ARAÚJO, Guilherme Santos., Reflexões para uma sociologia da dança. In: CÂMARA, Antônio da Silva; SILVA, Bruno Evangelista da; LESSA, Rodrigo Oliveira. (Orgs.). Ensaios de Sociologia da Arte. Salvador: EDUFBA, 2018, p. 217238.

CÂMARA, Antônio da Silva; SILVA, Bruno Evangelista da; LESSA, Rodrigo Oliveira. (Orgs.). Ensaios de Sociologia da Arte. Salvador: EDUFBA, 2018. 260p.

DEWEY, John. Arte como experiência. São Paulo: Martins Fontes, 2010

HEGEL, Gerog H. Estética I: introducción. Buenos Aires: Siglo Veinte, 1983.

KANT, Immanuel. Crítica da razão pura. Lisboa: Fundação Caloust Gulbenkian, 1989.

LESSA, Rodrigo Oliveira; JUNIOR, Humberto Alves Silva; MATHIAS, Pérola Virginia de Clemente. Aportes do materialismo histórico para a sociologia da arte. In: CÂMARA, Antônio da Silva; SILVA, Bruno Evangelista da; LESSA, Rodrigo Oliveira. (Orgs.). Ensaios de Sociologia da Arte. Salvador: EDUFBA, 2018, p.35-60.

LUKÁCS, Georg. Introdução a uma estética marxista: sobre a categoria da peculiaridade. Rio de Janeiro: Civilização Brasileira: 1968.

MALIN, Betty. Considerações acerca do sujeito da criação artística. In: CÂMARA, Antônio da Silva; SILVA, Bruno Evangelista da; LESSA, Rodrigo Oliveira. (Orgs.). Ensaios de Sociologia da Arte. Salvador: EDUFBA, 2018, p. 61-84.

PEIXOTO, Sergio Elísio. Notas sobre uma sociologia do cinema. In: CAMARA, Antônio da Silva; SILVA, Bruno Evangelista da; LESSA, Rodrigo Oliveira. (Orgs.). Ensaios de Sociologia da Arte. Salvador: EDUFBA, 2018, p.161-184.

ROCHA, Daniel. Apontamentos sobre sociologia do teatro. In: CÂMARA, Antônio da Silva; SILVA, Bruno Evangelista da; LESSA, Rodrigo Oliveira. (Orgs.). Ensaios de Sociologia da Arte. Salvador: EDUFBA, 2018, p.205-216.

SILVA, Bruno Evangelista da. Por uma sociologia da pintura. In: CÂMARA, Antônio da Silva; SILVA, Bruno Evangelista da; LESSA, Rodrigo Oliveira. (Orgs.). Ensaios de Sociologia da Arte. Salvador: EDUFBA, 2018, p.107-126.

Caroline de Araújo Lima - Doutora em Ciências Sociais pela UFBA (2020). Mestre em História Regional e Local pela UNEB (2010). Professora Assistente da UNEB, em Regime de Dedicação Exclusiva, lotada no Departamento de Ciências Humanas e Tecnologias (Campus XVIII), atua nos grupos de pesquisa Representações sociais: arte, ciência e ideologia (UFBA) e ProjetAH - História das Mulheres, Gênero, Imagens, Sertões.

Lucas Barreto Catalan - Mestre em Ciências Sociais pela Universidade Federal da Bahia. Integra o grupo de estudos Representações Sociais: Arte, Ciências e Ideologia, desenvolvendo pesquisas na área de Cinema, Cinema Latino-americano. Atualmente faz doutoramento em Ciências Socias, cuja pesquisa traz como tema "Ficção científica e distopia no cinema: pode o futuro antecipar o presente?" 
